\title{
Review Article \\ Physical Activity and Blood Lipids and Lipoproteins in Dialysis Patients
}

\author{
Hiroyuki Imamura, ${ }^{1}$ Keiko Mizuuchi, ${ }^{2}$ and Reika Oshikata ${ }^{3}$ \\ ${ }^{1}$ Department of Health and Nutrition, Faculty of Health Management, Nagasaki International University, \\ 2825-7 Huis Ten Bosch, Sasebo-shi, Nagasaki 859-3298, Japan \\ ${ }^{2}$ School of Nursing, Fukuyama Heisei University, 117-1 Masado Kamiiwanari, Miyuki-cho, \\ Fukuyama-shi, Hiroshima 720-0001, Japan \\ ${ }^{3}$ Faculty of Life Sciences, Seika Women's Junior College, 2-12-1 Minami Hachiman-cho, \\ Hakata-ku, Fukuoka 812-0886, Japan
}

Correspondence should be addressed to Hiroyuki Imamura, himamura@niu.ac.jp

Received 24 January 2012; Accepted 2 August 2012

Academic Editor: Jaime Uribarri

Copyright (C) 2012 Hiroyuki Imamura et al. This is an open access article distributed under the Creative Commons Attribution License, which permits unrestricted use, distribution, and reproduction in any medium, provided the original work is properly cited.

The relationship between physical activity and blood lipids and lipoproteins in dialysis patients is reviewed in the context of the potentially confounding factors such as nutritional intake, cigarette smoking, obesity, alcohol intake, and physical activity levels in the general population and additional confounding factors such as mode of dialysis and diabetes in dialysis patients. The known associations in the general population of physical activity with high-density-lipoprotein cholesterol subfractions and apolipoprotein A-I are more pronounced in hemodialysis patients than in peritoneal dialysis patients even after adjusting for these confounding factors. Examining studies on the effects of physical activity on blood lipids and lipoproteins, the most consistent observation is the noted decrease in triglycerides and increase in high-density-lipoprotein cholesterol and insulin sensitivity in hemodialysis patients. The changes in lipids and lipoproteins in hemodialysis patients could be caused by changes in activity levels of lipoprotein lipase, insulin sensitivity, and/or glucose metabolism. Future research investigating the relationship between physical activity and blood lipids and lipoproteins in dialysis patients should direct research towards the underlying mechanisms for changes in blood lipids and lipoproteins.

\section{Introduction}

Atherosclerotic heart disease is the leading cause of mortality among patients with chronic kidney disease [1-3]. Chronic kidney disease is associated with dyslipidemia, which seems to persist as renal failure advances and continues to affect clinical outcomes in patients on hemodialysis (HD) and peritoneal dialysis (PD) [4-13]. Patients on HD and PD are at increased risk for atherosclerotic heart disease, which is due at least in part to atherogenic lipid and lipoprotein abnormalities [1]. One study [14] compared traditional atherosclerotic heart disease risk factors among new dialysis patients with those in the general population and reported that the dialysis patients had a high prevalence of diabetes, hypertension, low physical activity, low high-density-lipoprotein cholesterol (HDL-C), and high triglycerides (TG). Exercise capacity as measured by maximal oxygen uptake in HD and PD patients is lower than in sedentary normal controls [15], but dialysis patients regardless of the treatment mode could benefit from appropriate exercise training in order to increase physical working capacity [16-18]. The positive association of physical activity with HDL-C has been reported in the general population [19-21]. Although a number of studies have reported blood lipid and lipoprotein profiles of HD and PD patients [5-13, 22], very little is known about how physical activity is related to or affects lipid and lipoprotein abnormalities in dialysis patients [22-25]. The purpose of this study was to review the scientific literature concerning the relationship between physical activity and blood lipids and lipoproteins in dialysis patients. 


\section{Confounding Factors in the General Population}

When evaluating the predictive power of a certain risk factor, a variation in the factor can be influenced by a simultaneous variation in other possible confounding factors. Thus, it is important to adjust other confounding factors to examine the relationship of physical activity with blood lipids and lipoproteins.

2.1. Nutrition. It has been suggested that higher intake of $n$ 3 polyunsaturated fatty acids and lower intakes of n- 6 polyunsaturated fatty acids and saturated fatty acids have preventive effects on coronary heart disease [26-30]. Saturated fatty acids, cholesterol, and excess caloric intake raise serum lowdensity-lipoprotein cholesterol (LDL-C) [31]. Consumption of fruit and vegetables is inversely related to LDL-C [32-34]. In addition, individuals consuming a high-carbohydrate diet tend to show lower HDL-C than those who consume a lowcarbohydrate diet $[35,36]$.

2.2. Cigarette Smoking. In studies at our laboratory [37-40], we reported that cigarette smoking was negatively associated with HDL-C [37] and positively with TG [37-40]. Cigarette smokers show significantly higher TG and lower HDL-C and/or $\mathrm{HDL}_{2}$-C [37-40].

2.3. Obesity. Obese subjects, in comparison with their counterparts, tend to show higher TC, TG, and LDL-C and/or lower HDL-C [41-46]. It has been reported that the percentage of body fat showed a significant positive correlation with TG and a negative correlation with HDL-C after adjusting for age and maximal oxygen uptake [47-49]. It has also been reported that body mass index (BMI) was positively related to LDL-C and TG [50].

2.4. Alcohol Intake. It has been reported that alcohol consumption was positively associated with $\mathrm{HDL}, \mathrm{HDL}_{2}$, and/or $\mathrm{HDL}_{3}$ [51-53]. Alcohol drinkers show a higher HDL-C than nondrinkers [54-58].

\section{Confounding Factors in Dialysis Patients}

The relationships of confounding factors with blood lipids and lipoproteins in dialysis patients have not been investigated sufficiently in contrast to the above studies on the general population.

3.1. Mode of Dialysis. Both HD and PD patients exhibit a more atherogenic lipid profile, such as increased serum TG, and decreased apolipoprotein (apo) A and/or HDL-C [5-13] than healthy controls. However, PD patients exhibit a more atherogenic lipid profile than HD patients $[10,11,13,22]$. The cause of the worsening of lipid profile in PD patients may be multifactorial. First, PD patients have increased lipoprotein substrate availability through glucose uptake from the peritoneal dialysis fluid, which may contribute to increased hepatic synthesis of apo B-containing lipoproteins $[59,60]$.
Second, it may be related to the loss of large molecular weight substances in the peritoneal dialysis fluid $[59,60]$. The daily clearance of apo A-I has been reported to be twofold to fourfold greater than that of apo B $[61,62]$. Third, it has been reported that the PD patients had significantly higher apo CIII than HD patients [11], which may suggest that removal of TG-rich lipoproteins may be less efficient in the PD patients than HD patients because apo CIII inhibits lipoprotein lipase (LPL). LPL hydrolyzes both chylomicron and VLDL on the vascular endothelium and generates precursor of HDL during lipolysis of TG-rich lipoproteins [63]. Thus, decrease in this enzyme activity may decrease HDL-C and increase TG.

3.2. Diabetes. Sakurai et al. [8] compared lipid, apoprotein, and associated enzyme activities in 5 groups of subjects: nondiabetic end-stage renal disease (ESRD) patients with HD, nondiabetic ESRD patients without HD, diabetic ESRD patients with HD, diabetic ESRD patients without HD, and normal controls. The results showed that the 2 groups of nondiabetic ESRD with or without HD exhibited significantly higher serum TG and apo C-III and lower HDL-C, apo A-I, apo A-II, apo E, and LCAT activities than the controls. LPL activity was significantly lower in undialysed patient groups than the controls, whereas such differences were not found in dialysed patients groups. Hepatic triglyceride lipase activity was decreased in all 4 patient groups compared with that in controls. Patients with diabetic ESRD exhibited significantly higher serum apo B than controls, besides the lipid and apo abnormalities observed in nondiabetic ESRD patients. The apo B/apo A-I ratio was significantly higher in diabetic ESRD patient groups than in nondiabetic patient groups undergoing HD. These results indicate that lipid abnormalities are accelerated in diabetic ESRD patients.

\section{Relationship of Physical Activity with Blood Lipids and Lipoproteins}

4.1. General Population. It has been reported that physical activity was positively associated with HDL-C [19-21]. Active people in comparison with sedentary people tend to show lower TC and TG and/or higher HDL-C [64-67].

4.2. Dialysis Patients. In a study at our laboratory [21], we reported the relationship of physical activity, as measured by steps/day, with HDL-C subfractions and LCAT activity in 35 $\mathrm{HD}$ and $26 \mathrm{PD}$ patients. In this study, nutrient and dietary intake, proportions of drinkers, smokers, and men and women did not differ between HD and PD patient groups. Furthermore, these variables did not correlate with any of the serum lipids, lipoproteins, and LCAT activity. Thus, influences of these variables appear to be limited. However, HD patients had significantly higher mean age and duration of dialysis treatment and had lower mean BMI and steps/day than PD patients, so that analysis was performed separately for HD and PD by computer. The results showed that, when possible confounding factors (LCAT activity, logarithmic transformation of TG, age, and gender) were included in the 
stepwise multiple regression analyses, in HD patients, steps/ day was significantly positively correlated with $\mathrm{HDL}_{2}-\mathrm{C}$ and apo A-I, while it was significantly positively correlated with $\mathrm{HDL}_{3}-\mathrm{C}$ in $\mathrm{PD}$ patients. When subjects were subdivided into 3 groups according to steps/day, in HD patients, the highest category of steps/day had significantly higher $\mathrm{HDL}_{2}-\mathrm{C}$ and apo A-I than the lowest category, while such results were not observed in PD patients. These results suggest that the known associations in the general population of physical activity with HDL-C subfractions and apo A-I are more pronounced in HD patients than in PD patients. However, it needs to be mentioned that because the sample size is small in this study, further studies are needed to make firm conclusion.

\section{Effects of Physical Exercise on Blood Lipids and Lipoproteins}

5.1. General Population. It has been reported that aerobic training increases HDL-C $[68,69]$ and lowers TG, LDL-C, and/or VLDL-C [69, 70].

5.2. Hemodialysis Patients. Goldberg et al., using 6 [23] or 7 [24] subjects, examined the metabolic effects of exercise training in HD patients and reported that training lowered TG and increased HDL-C. In a subsequent study, Goldberg et al. [25] examined the effects of exercise on plasma lipids and lipoproteins in $25 \mathrm{HD}$ patients. Patients were randomized into comparable exercising $(n=14)$ and sedentary control $(n=11)$ groups. All training sessions were held indoors, 3 times weekly for a mean of $12 \pm 4$ (SD) months, on a 17 lap/mile track. The results showed that maximal oxygen uptake significantly increased $21 \%$, and the durations for the graded exercise stress test significantly improved 19\% in exercising group, but did not change in controls. Plasma TG significantly decreased $37 \%$. No change in TC or LDL-C was noted; however, HDL-C significantly increased $17 \%$ in the exercising group. Furthermore, fasting plasma insulin significantly decreased $20 \%$ and glucose disappearance rates significantly improved $42 \%$. Such changes were not observed in the control group.

\section{Mechanisms for Changes in Blood Lipids and Lipoproteins in Dialysis Patients}

Several possible mechanisms that could explain how physical activity changes blood lipids and lipoproteins in dialysis patients have been proposed by Goldberg et al. [23]. First, they could be caused by changes in activity levels of LPL. Kantor et al. [71], using 10 well-trained men, reported that LPL activity was nearly doubled after participating in a marathon and suggested that increase in LPL activity probably mediated the increase in HDL-C. However, the relationship of physical activity with LPL activity has never been investigated in dialysis patients.

Second, it is also possible that they could be indirectly and/or directly caused by improvements of insulin sensitivity and glucose metabolism [23]. The elevation in plasma insulin may contribute to the lipid abnormalities observed in dialysis patients by promoting the synthesis and production of TG-rich lipoproteins by the liver. Goldberg et al. [23], using $6 \mathrm{HD}$ patients, examined the metabolic effects of exercise training and reported that there was a $23 \%$ improvement in glucose tolerance and a $40 \%$ reduction in hyperinsulinism with no significant changes in body weight or diet.

\section{Directions for Future Research}

It is suggested that, in dealing with hyperlipoproteinemia, the first principle is the provision of a diet $[72,73]$ and the maintenance of a good exercise and physical fitness program. However, the relationships of physical activity with blood lipids and lipoproteins and effects of exercise training on dialysis patients have not been investigated sufficiently in contrast to that in the general population. For HD patients, it is suggested that the intensity of exercise should be between $65 \%$ and $85 \%$ of maximal levels, as determined from exercise testing. Interval work varying the exercise intensity between "target" intensity and lower for durations of 5 minutes may be necessary initially. The goal of 30 to 45 minutes of exercise at target intensity per session, 3 sessions per week, should be attained [74].

Future research investigating the relationship between physical activity and blood lipids and lipoproteins in dialysis patients should include (i) studies designed to investigate the relationships of physical activity with blood lipids and lipoproteins after adjusting for other possible confounding factors, (ii) effects of exercise training on blood lipids and lipoproteins, and (iii) directing research towards the underlying mechanisms for changes in blood lipids and lipoproteins. These studies should, in particular, focus on adolescents and young adults since there is a paucity of information in the literature in this area.

\section{References}

[1] S. S. Prichard, "Impact of dyslipidemia in end-stage renal disease," Journal of the American Society of Nephrology, vol. 14, no. 9, supplement 4, pp. S315-S320, 2003.

[2] R. N. Foley, P. S. Parfrey, and M. J. Sarnak, "Epidemiology of cardiovascular disease in chronic renal disease," Journal of the American Society of Nephrology, vol. 9, no. 12, supplement, pp. S16-S23, 1998.

[3] C. A. Herzog, J. Z. Ma, and A. J. Collins, "Poor long-term survival after acute myocardial infarction among patients on long-term dialysis," The New England Journal of Medicine, vol. 339, no. 12, pp. 799-805, 1998.

[4] E. Kimak and J. Solski, "ApoA- and apoB-containing lipoproteins and $\operatorname{Lp}(\mathrm{a})$ concentration in non-dialyzed patients with chronic renal failure," Renal Failure, vol. 24, no. 4, pp. 485492, 2002.

[5] T. Shoji, Y. Nishizawa, T. Kawagishi et al., "Atherogenic lipoprotein changes in the absence of hyperlipidemia in patients with chronic renal failure treated by hemodialysis," Atherosclerosis, vol. 131, no. 2, pp. 229-236, 1997.

[6] G. Monzani, F. Bergesio, R. Ciuti et al., "Lipoprotein abnormalities in chronic renal failure and dialysis patients," Blood Purification, vol. 14, no. 3, pp. 262-272, 1996. 
[7] M. R. Yiǧitoğlu, M. F. Polat, F. Akçay, Z. Ari, B. S. Uyanik, and H. M. Özilgili, "Increased lipoprotein (a) and its relationships with other parameters of lipoprotein metabolism in chronic renal failure treated by hemodialysis," Japanese Heart Journal, vol. 38, no. 1, pp. 83-89, 1997.

[8] T. Sakurai, T. Oka, H. Hasegawa, N. Igaki, S. Miki, and T. Goto, "Comparison of lipids, apoproteins and associated enzyme activities between diabetic and nondiabetic end-stage renal disease," Nephron, vol. 61, no. 4, pp. 409-414, 1992.

[9] E. Kimak, J. Solski, L. Janicka, A. Ksaziek, and K. Janicki, "Concentration of $\mathrm{Lp}(\mathrm{a})$ and other apolipoproteins in predialysis, hemodialysis, chronic ambulatory peritoneal dialysis and post-transplant patients," Clinical Chemistry and Laboratory Medicine, vol. 38, no. 5, pp. 421-425, 2000.

[10] K. C. Siamopoulos, M. S. Elisaf, H. T. Bairaktari, M. B. Pappas, G. D. Sferopoulos, and N. G. Nikolakakis, "Lipid parameters including lipoprotein (a) in patients undergoing CAPD and hemodialysis," Peritoneal Dialysis International, vol. 15, no. 8, pp. 342-347, 1995.

[11] P. O. A. Attman, O. G. Samuelsson, J. Moberly et al., "Apolipoprotein B-containing lipoproteins in renal failure: the relation to mode of dialysis," Kidney International, vol. 55, no. 4, pp. 1536-1542, 1999.

[12] T. Shoji, Y. Nishizawa, H. Nishitani, M. Yamakawa, and H. Morii, "Impaired metabolism of high density lipoprotein in uremic patients," Kidney International, vol. 41, no. 6, pp. 1653 1661, 1992.

[13] J. B. Moberly, P. O. Attman, O. Samuelsson, A. C. Johansson, C. Knight-Gibson, and P. Alaupovic, "Alterations in lipoprotein composition in peritoneal dialysis patients," Peritoneal Dialysis International, vol. 22, no. 2, pp. 220-228, 2002.

[14] J. C. Longenecker, J. Coresh, N. R. Powe et al., "Traditional cardiovascular disease risk factors in dialysis patients compared with the general population: the CHOICE study," Journal of the American Society of Nephrology, vol. 13, no. 7, pp. 19181927, 2002.

[15] P. Painter, D. Messer-Rehak, P. Hanson et al., "Exercise capacity in hemodialysis, CAPD, and renal transplant patients," Nephron, vol. 42, no. 1, pp. 47-51, 1986.

[16] P. Koufaki, T. H. Mercer, P. F. Naish et al., "Effects of exercise training on aerobic and functional capacity of end-stage renal disease patients," Clinical Physiology and Functional Imaging, vol. 22, no. 2, pp. 115-124, 2002.

[17] A. Deligiannis, E. Kouidi, E. Tassoulas, P. Gigis, A. Tourkantonis, and A. Coats, "Cardiac effects of exercise rehabilitation in hemodialysis patients," International Journal of Cardiology, vol. 70, no. 3, pp. 253-266, 1999.

[18] E. Konstantinidou, G. Koukouvou, E. Kouidi, A. Deligiannis, and A. Tourkantonis, "Exercise training in patients with endstage renal disease on hemodialysis: comparison of three rehabilitation programs," Journal of Rehabilitation Medicine, vol. 34, no. 1, pp. 40-45, 2002.

[19] M. Yao, A. H. Lichtenstein, S. B. Roberts et al., "Relative influence of diet and physical activity on cardiovascular risk factors in urban Chinese adults," International Journal of Obesity, vol. 27, no. 8, pp. 920-932, 2003.

[20] O. H. Forde, D. S. Thelle, E. Arnesen, and O. D. Mjos, "Distribution of high density lipoprotein cholesterol according to relative body weight, cigarette smoking and leisure time physical activity," Acta Medica Scandinavica, vol. 219, no. 2, pp. 167-171, 1986.

[21] K. Yano, D. M. Reed, J. D. Curb et al., "Biological and dietary correlates of plasma lipids and lipoproteins among elderly
Japanese men in Hawaii," Arteriosclerosis, vol. 6, no. 4, pp. 422433, 1986.

[22] R. Masuda, H. Imamura, K. Mizuuchi, K. Miyahara, H. Kumagai, and H. Hirakata, "Physical activity, high-density lipoprotein cholesterol subfractions and lecithin: cholesterol acyltransferase in dialysis patients," Nephron Clinical Practice, vol. 111, no. 4, pp. c253-c259, 2009.

[23] A. P. Goldberg, J. M. Hagberg, J. A. Delmez et al., "Metabolic effects of exercise training in hemodialysis patients," Kidney International, vol. 18, no. 6, pp. 754-761, 1980.

[24] A. P. Goldberg, J. M. Hagberg, J. A. Delmez et al., "The metabolic and psychological effects of exercise training in hemodialysis patients," American Journal of Clinical Nutrition, vol. 33, no. 7, pp. 1620-1628, 1980.

[25] A. P. Goldberg, E. M. Geltman, J. M. Hagberg et al., "Therapeutic benefits of exercise training for hemodialysis patients," Kidney International, vol. 24, no. 16, pp. S-303-S-309, 1983.

[26] D. Mozaffarian, A. Ascherio, F. B. Hu et al., "Interplay between different polyunsaturated fatty acids and risk of coronary heart disease in men," Circulation, vol. 111, no. 2, pp. 157-164, 2005.

[27] R. N. Lemaitre, I. B. King, D. Mozaffarian, L. H. Kuller, R. P. Tracy, and D. S. Siscovick, "N-3 polyunsaturated fatty acids, fatal ischemic heart disease, and nonfatal myocardial infarction in older adults: The Cardiovascular Health Study," American Journal of Clinical Nutrition, vol. 77, no. 2, pp. 319325, 2003.

[28] J. L. Breslow, "N-3 Fatty acids and cardiovascular disease," American Journal of Clinical Nutrition, vol. 83, no. 6, supplement, pp. 1477S-1482S, 2006.

[29] F. B. Hu, L. Bronner, W. C. Willett et al., "Fish and omega-3 fatty acid intake and risk of coronary heart disease in women," Journal of the American Medical Association, vol. 287, no. 14, pp. 1815-1821, 2002.

[30] T. Nakamura, A. Azuma, T. Kuribayashi, H. Sugihara, S. Okuda, and M. Nakagawa, "Serum fatty acid levels, dietary style and coronary heart disease in three neighbouring areas in Japan: the Kumihama study," British Journal of Nutrition, vol. 89, no. 2, pp. 267-272, 2003.

[31] S. M. Grundy and M. A. Denke, "Dietary influences on serum lipids and lipoproteins," Journal of Lipid Research, vol. 31, no. 7, pp. 1149-1172, 1990.

[32] L. Djoussé, D. K. Arnett, H. Coon, M. A. Province, L. L. Moore, and R. C. Ellison, "Fruit and vegetable consumption and LDL cholesterol: The National Heart, Lung, and Blood Institute Family Heart Study," American Journal of Clinical Nutrition, vol. 79, no. 2, pp. 213-217, 2004.

[33] R. B. Singh, S. S. Rastogi, M. A. Niaz, S. Ghosh, R. Singh, and S. Gupta, "Effect of fat-modified and fruit- and vegetableenriched diets on blood lipids in the Indian Diet Heart Study," American Journal of Cardiology, vol. 70, no. 9, pp. 869-874, 1992.

[34] R. B. Singh, S. Ghosh, and R. Singh, "Effects on serum lipids of adding fruits and vegetables to prudent diet in the Indian experiment of infarct survival (IEIS)," Cardiology, vol. 80, no. 3-4, pp. 283-293, 1992.

[35] A. T. Merchant, S. S. Anand, L. E. Kelemen et al., "Carbohydrate intake and HDL in a multiethnic population," American Journal of Clinical Nutrition, vol. 85, no. 1, pp. 225-230, 2007.

[36] N. M. McKeown, J. B. Meigs, S. Liu et al., "Dietary carbohydrates and cardiovascular disease risk factors in the Framingham offspring cohort," Journal of the American College of Nutrition, vol. 28, no. 2, pp. 150-158, 2009. 
[37] H. Imamura, K. Tanaka, C. Hirae et al., "Relationship of cigarette smoking to blood pressure and serum lipids and lipoproteins in men," Clinical and Experimental Pharmacology and Physiology, vol. 23, no. 5, pp. 397-402, 1996.

[38] H. Imamura, K. Teshima, N. Miyamoto, and T. Shirota, "Cigarette smoking, high-density lipoprotein cholesterol subfractions, and lecithin: cholesterol acyltransferase in young women," Metabolism, vol. 51, no. 10, pp. 1313-1316, 2002.

[39] H. Imamura, K. Uchida, and D. Kobata, "Relationship of cigarette smoking with blood pressure, serum lipids and lipoproteins in young Japanese women," Clinical and Experimental Pharmacology and Physiology, vol. 27, no. 5-6, pp. 364-369, 2000.

[40] H. Imamura, K. Miyahara, A. Nagata et al., "Cigarette smoking, HDL-C subfractions, and lecithin:cholesterol acyltransferase in collegiate men," Health Evaluation and Promotion, vol. 39, pp. 535-539, 2012.

[41] J. R. Ortlepp, J. Metrikat, M. Albrecht, P. Maya-Pelzer, H. Pongratz, and R. Hoffmann, "Relation of body mass index, physical fitness, and the cardiovascular risk profile in 3127 young normal weight men with an apparently optimal lifestyle," International Journal of Obesity, vol. 27, no. 8, pp. 979$982,2003$.

[42] N. Nakanishi, K. Nakamura, S. Ichikawa, K. Suzuki, and K. Tatara, "Relationship between lifestyle and serum lipid and lipoprotein levels in middle-aged Japanese men," European Journal of Epidemiology, vol. 15, no. 4, pp. 341-348, 1999.

[43] H. Schröder, J. Marrugat, R. Elosua, and M. I. Covas, "Relationship between body mass index, serum cholesterol, leisuretime physical activity, and diet in a Mediterranean SouthernEurope population," British Journal of Nutrition, vol. 90, no. 2, pp. 431-439, 2003.

[44] A. Taniguchi, M. Fukushima, M. Sakai et al., "The role of the body mass index and triglyceride levels in identifying insulin-sensitive and insulin-resistant variants in Japanese non-insulin-dependent diabetic patients," Metabolism, vol. 49, no. 8 , pp. 1001-1005, 2000.

[45] T. Kamihama, H. Imamura, C. Nishimura et al., "Relationship between body mass index and blood pressure, serum lipids and lipoproteins in young Japanese women," Health Evaluation Promotion, vol. 29, pp. 519-521, 2002 (Japanese).

[46] T. Kamihama, H. Imamura, C. Nishimura et al., "Relationship between body mass index and blood pressure, serum lipids and lipoproteins in young Japanese men," Health Evaluation Promotion, vol. 29, pp. 592-595, 2002 (Japanese).

[47] H. Imamura, M. Matsubara, M. Minayoshi et al., "A criterion for evaluation of obesity based on the relationship between percent body fat and medical examination parameters," The Japanese Journal of Physical Fitness and Sports Medicine, vol. 41, pp. 70-78, 1992 (Japanese).

[48] H. Imamura, M. Matsubara, M. Minayoshi et al., "A criterion for evaluation of obesity in men based on the relationship between percent body fat and medical examination parameters," Japanese Journal of Physical Fitness and Sports Medicine, vol. 41, pp. 322-329, 1992 (Japanese).

[49] K. Teshima, H. Imamura, K. Uchida et al., "Relationship of simple predictors of obesity with coronary heart disease risk factors and nutrient intake in collegiate women," Health Evaluation Promotion, vol. 31, pp. 463-468, 2004 (Japanese).

[50] R. P. Donahue, T. J. Orchard, L. H. Kuller, and A. L. Drash, "Lipids and lipoproteins in a young adult population. The Beaver County Lipid Study," American Journal of Epidemiology, vol. 122, no. 3, pp. 458-467, 1985.
[51] J. M. Gaziano, J. E. Buring, J. L. Breslow et al., "Moderate alcohol intake, increased levels of high-density lipoprotein and its subfractions, and decreased risk of myocardial infarction," The New England Journal of Medicine, vol. 329, no. 25, pp. 1829-1834, 1993.

[52] M. Russell, M. L. Cooper, M. R. Frone, and J. W. Welte, "Alcohol drinking patterns and blood pressure," American Journal of Public Health, vol. 81, no. 4, pp. 452-457, 1991.

[53] P. T. Williams, K. M. Vranizan, M. A. Austin, and R. M. Krauss, "Associations of age, adiposity, alcohol intake, menstrual status, and estrogen therapy with high-density lipoprotein subclasses," Arteriosclerosis and Thrombosis, vol. 13, no. 11, pp. 1654-1661, 1993.

[54] C. Nishimura, H. Imamura, K. Uchida et al., "The relationship of alcohol intake to blood pressure and serum lipids and lipoprotein in men," Japanese Journal of Multiphasic Health Testing and Services, vol. 26, pp. 144-149, 1999 (Japanese).

[55] C. Nishimura, H. Imamura, Y. Masuda et al., "The relationship of alcohol intake to blood pressure and serum lipids and lipoprotein in women," Japanese Journal of Multiphasic Health Testing and Services, vol. 27, pp. 260-264, 2000 (Japanese).

[56] P. T. Williams, "Interactive effects of exercise, alcohol, and vegetarian diet on coronary artery disease risk factors in 9242 runners: The National Runners' Health Study," American Journal of Clinical Nutrition, vol. 66, no. 5, pp. 1197-1206, 1997.

[57] S. R. Choudhury, H. Ueshima, Y. Kita et al., "Alcohol intake and serum lipids in a Japanese population," International Journal of Epidemiology, vol. 23, no. 5, pp. 940-947, 1994.

[58] R. D. Langer, M. H. Criqui, and D. M. Reed, "Lipoproteins and blood pressure as biological pathways for effect of moderate alcohol consumption on coronary heart disease," Circulation, vol. 85, no. 3, pp. 910-915, 1992.

[59] P. O. Attman, O. Samuelsson, and P. Alaupovic, "Diagnosis and classification of dyslipidemia in renal disease," Blood Purification, vol. 14, no. 1, pp. 49-57, 1996.

[60] D. C. Wheeler, "Abnormalities of lipoprotein metabolism in CAPD patients," Kidney International, vol. 50, supplement 56, pp. S41-S46, 1996.

[61] K. Saku, J. Sasaki, S. Naito, and K. Arakawa, "Lipoprotein and apolipoprotein losses during continuous ambulatory peritoneal dialysis," Nephron, vol. 51, no. 2, pp. 220-224, 1989.

[62] A. Kandoussi, C. Cachera, R. Reade, D. Pagniez, J. C. Fruchart, and A. Tacquet, "Apo AIV in plasma and dialysate fluid of CAPD patients: comparison with other apolipoproteins," Nephrology Dialysis Transplantation, vol. 7, no. 10, pp. 10261029, 1992.

[63] G. Franceschini, P. Maderna, and C. R. Sirtori, "Reverse cholesterol transport: physiology and pharmacology," Atherosclerosis, vol. 88, no. 2-3, pp. 99-107, 1991.

[64] P. D. Wood and W. L. Haskell, "The effect of exercise on plasma high density lipoproteins," Lipids, vol. 14, no. 4, pp. 417-427, 1979.

[65] C. Nishimura, H. Imamura, Y. Komatsu et al., "Physical fitness, blood properties, and nutritional intake of female college soccer players," Journal of Exercise Sports Physiology, vol. 2, pp. 159-166, 1995 (Japanese).

[66] E. Suter and M. R. Hawes, "Relationship of physical activity, body fat, diet, and blood lipid profile in youths 10-15 yr," Medicine and Science in Sports and Exercise, vol. 25, no. 6, pp. 748-754, 1993.

[67] J. Skoumas, C. Pitsavos, D. B. Panagiotakos et al., "Physical activity, high density lipoprotein cholesterol and other lipids 
levels, in men and women from the ATTICA study," Lipids in Health and Disease, vol. 2, article 1, 2003.

[68] S. Kodama, S. Tanaka, K. Saito et al., "Effect of aerobic exercise training on serum levels of high-density lipoprotein cholesterol: a meta-analysis," Archives of Internal Medicine, vol. 167, no. 10, pp. 999-1008, 2007.

[69] J. L. Durstine, P. W. Grandjean, P. G. Davis, M. A. Ferguson, N. L. Alderson, and K. D. DuBose, "Blood lipid and lipoprotein adaptations to exercise: a quantitative analysis," Sports Medicine, vol. 31, no. 15, pp. 1033-1062, 2001.

[70] H. Yoshida, T. Ishikawa, M. Suto et al., "Effects of supervised aerobic exercise training on serum adiponectin and parameters of lipid and glucose metabolism in subjects with moderate dyslipidemia," Journal of Atherosclerosis and Thrombosis, vol. 17, no. 11, pp. 1160-1166, 2010.

[71] M. A. Kantor, E. M. Cullinane, P. N. Herbert, and P. D. Thompson, "Acute increase in lipoprotein lipase following prolonged exercise," Metabolism, vol. 33, no. 5, pp. 454-457, 1984.

[72] E. Ritz, J. Augustin, J. Bommer et al., "Should hyperlipemia of renal failure be treated?” Kidney International, vol. 28, no. 17, supplement, pp. S-84-S-87, 1985.

[73] A. C. Goldberg and G. Schonfeld, "Effects of diet on lipoprotein metabolism," Annual Review of Nutrition, vol. 5, pp. 195212, 1985.

[74] P. Painter and S. W. Zimmerman, "Exercise in end-stage renal disease," American Journal of Kidney Diseases, vol. 7, no. 5, pp. 386-394, 1986. 


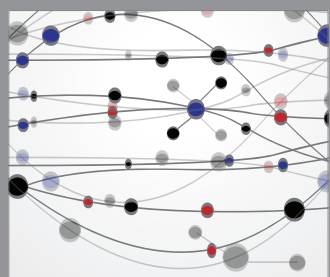

The Scientific World Journal
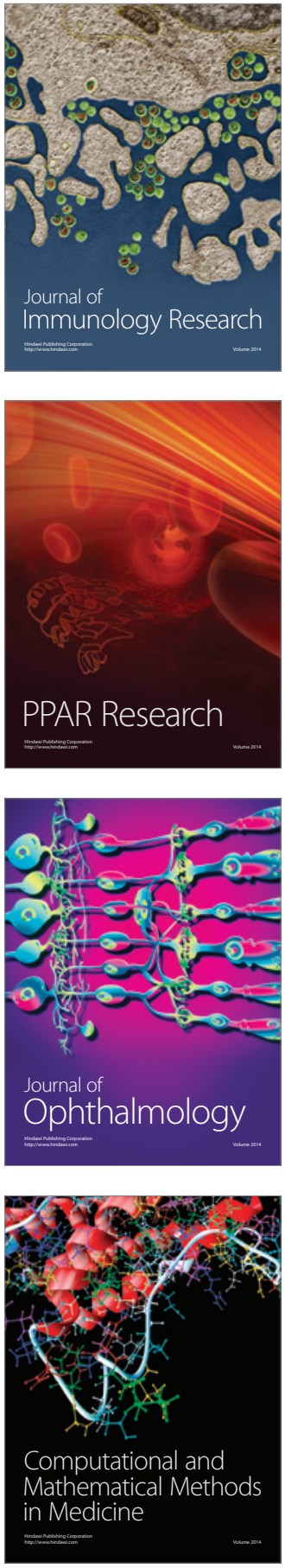

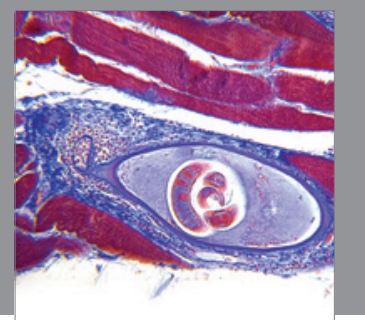

Gastroenterology

Research and Practice
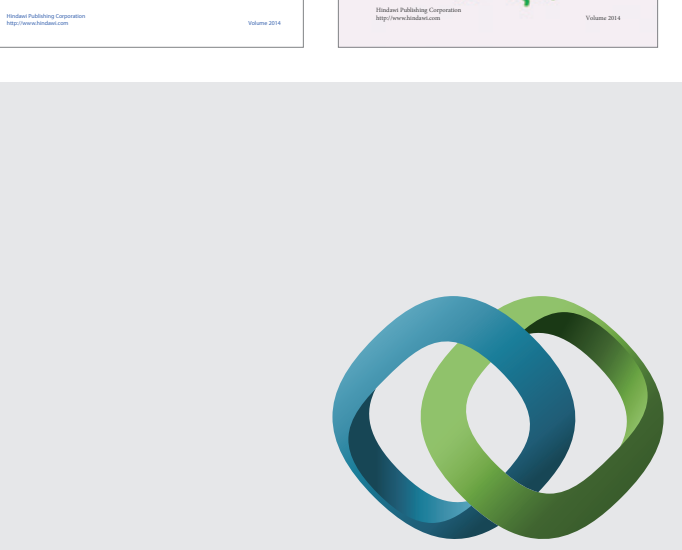

\section{Hindawi}

Submit your manuscripts at

http://www.hindawi.com
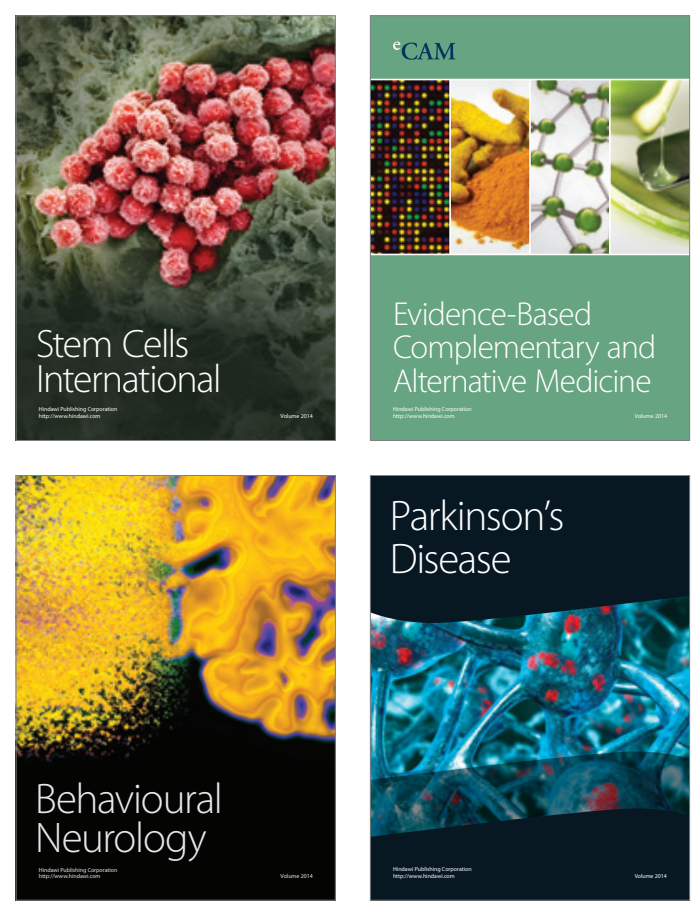

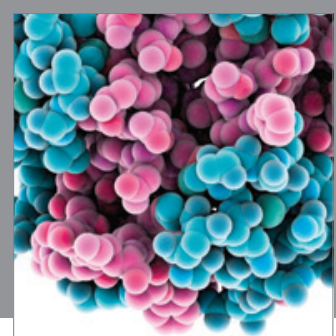

Journal of
Diabetes Research

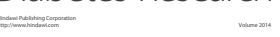

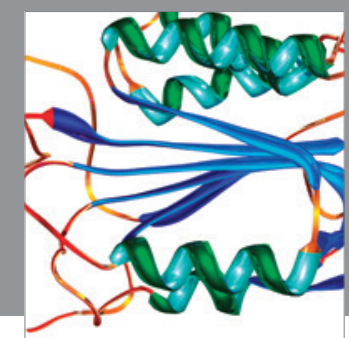

Disease Markers
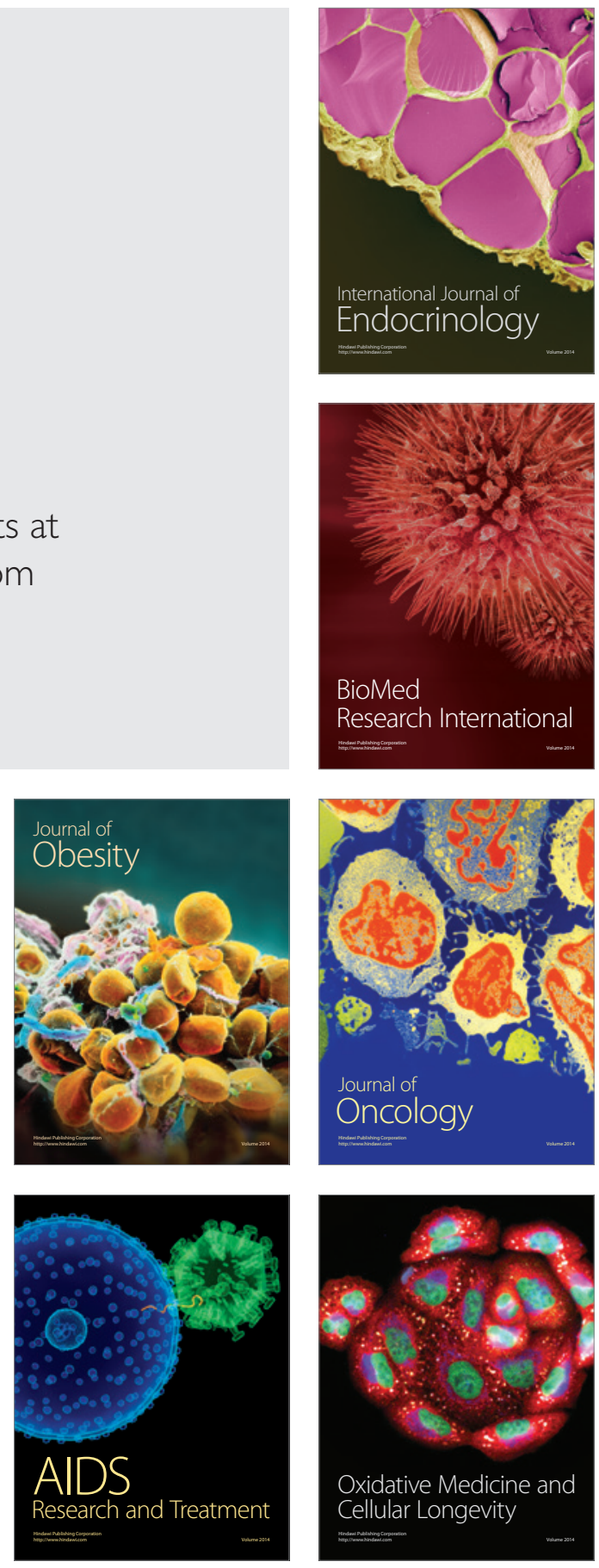